\title{
AVENTURAS ONÍRICAS Y VIAJES AL PASADO EN LA ETERNIDAD DE LA ROSA (2016)
}

\author{
Nicole HÄFFNER \\ Universidad del Sarre \\ nicole.haeffner@googlemail.com
}

Resumen: En la novela juvenil argentina La Eternidad de la Rosa (2016), los viajes oníricos al pasado son la clave para resolver el conflicto general de la narración que es un espíritu que busca ayuda por parte del protagonista y le causa pesadillas. El ensayo presenta la representación de esa combinación significativa de los motivos del sueño y del viaje, su contexto narrativo, su rol fundamental y su desarrollo en la trama. Además, se considera el tenor general de espiritualismo como característica de una posible nueva corriente literaria. Así, un nuevo proyecto social para las sociedades modernas se promueve en una mezcla de ficción y referencias a la realidad extra-ficcional. Se mostrarán igualmente los mecanismos que se usan para dirigirse a un público joven y darle acceso a ideas filosóficas, sin monólogos grandes, complejos y difíciles.

Palabras clave: sueño, viaje, literatura juvenil, espiritualismo, sociedad moderna

\section{AVENTURES ONIRIQUES ET VOYAGES AU PASSÉ DANS L'ÉTERNITÉ DE LA ROSE (2016)}

Résumé: Dans le roman de jeunesse L'Éternité de la Rose (2016), des voyages oniriques au passé sont la clé pour résoudre le conflict général de la narration. Il s' agit d'un esprit qui cherche de l'aide de la part du protagoniste et lui cause des cauchemars. L'article montre la représentation de cette combinaison significative des motifs du rêve et du voyage, son contexte narratif, son rôle fondamental et 
son développement dans l'action. De plus, se prend en considération la teneur générale de spiritualisme comme caractéristique d'un possible nouveau courant littéraire. Ainsi, un nouveau projet social pour les sociétés modernes est promu dans un mélange de fiction et de références à la réalité extra-fictionnelle. Également sont montrés les mécanismes utilisés pour se diriger à un public jeune et pour donner accès à des idées philosophiques sans de grands monologues complexes et difficiles.

Mots clés: rêve, voyage, littérature de jeunesse, spiritualisme, société moderne

\section{DREAMLIKE ADVENTURES AND TIME TRAVELING TO THE PAST IN THE ETERNITY OF THE ROSE (2016)}

Summary: In the Argentinian youth novel The Eternity of the Rose (2016), oneiric journeys to the past are the key for resolving the general conflict of the narration, which is a spirit that is looking for the help of the protagonist and causes him nightmares. The essay presents the representation of this significant combination of the motives of dream and travelling, its narrative context, its fundamental role and its development in the plot. Furthermore the general tenor of spiritualism is taken into consideration, as characteristic of a possible new literary tendency. Thus a new social project for the modern societies is promoted in a mixture of fiction and references to the extra-fictional reality. Also the mechanisms that are used to address a young public and to give access to philosophical ideas without big, complex and difficult monologues will be shown.

Keywords: dream, journey, youth literature, spiritualism, modern society

La novela juvenil argentina La Eternidad de la Rosa ${ }^{1}$ del año 2016, una co-producción de los autores Gabriel Moschitta y Laura González Roma, trata del joven Omar, al que le atormentan extrañas pesadillas. Por esta razón, acude al terapeuta parapsicólogo Fabio Zerpa, nombre de un personaje contemporáneo, real por cierto $^{2}$, para que lo libere de su sufrimiento y descubra el secreto que se esconde ahí detrás. La joven Paula, participante entusiasmada en uno de los seminarios espirituales de Zerpa, se interesa mucho por Omar y su problema y de este modo se desarrolla una historia de amor.

Se observa que las pesadillas de Omar son causadas por un alma que busca liberarse. Zerpa y una

1 Para facilitar la lectura citamos esa obra con la abreviación Rosa más el número de la página. 2 Cf. su página web, URL: http://www.fabiozerpa.com.ar/\#. Última consulta el 13-09-2018. 
psicóloga, Norma Nigro, tratan de resolver el enigma mediante «hipnosis regresiva[s] atenta[s]»o «sofrosis cuántica[s]» (las dos: Rosa 21). En esas sesiones el hipnotizado, y en cierto modo también sus terapeutas, viaja/n por tiempo y espacio a vidas pasadas, especialmente a una: la de un tal Ovidio Rebaudi. Este nombre igualmente pertenece a un personaje histórico, que vivió entre 1860 y 1931 . Se trata de un «médium» que es capaz de buscar espíritus y comunicarse con ellos. Se espera que por esas regresiones Omar pueda recuperar su propia «mediumnidad» (explícitamente, por ejemplo Rosa 57) para entender lo que necesita el alma.

Así, en la página 28, se efectúa la primera hipnosis regresiva. Con frases ritualizadas, típicas de una hipnosis, empieza el terapeuta a inducirlo y llevarlo primero a su propia infancia de esta vida: «Te encontrás completamente relajado, protegido por una luz violeta que cubre todo tu cuerpo [...], te sentís cómodo, tranquilo... en este instante tenés tres años y estás recordando una situación muy alegre.» (Rosa 28). Después, lo conduce al estado prenatal en el vientre de su mamá y al cabo de una hora, para la que no se especifica la actividad, se comenta por parte del narrador en focalización cero que «Omar comenzó a recordar sucesos trascendentes.» (Rosa 28). A la manera del estilo general de la novela, la narración vuelve al estilo directo y Omar cuenta desde su sueño o su visión hipnótica lo que ve: una sala llena de gente (Rosa 28). Este viaje onírico se presenta como intenso y con impacto físico, ya que el pulso del paciente indica una tensión alta. El hipnotizador puede, a su vez, comunicar con el hipnotizado, hacerle preguntas y servir de apoyo, aunque Omar esté solo en ese otro lugar (todavía) indefinido. Se construye cierto suspense al dar fragmentos de informaciones poco a poco: las personas lo consultan en cuanto a sus seres queridos. Una mujer llora por su hijo. Omar, en su manifestación de este «otro lado», busca al hijo con su mente, su espíritu, y lo encuentra, pero muerto (Rosa 29). Así que nos encontramos ante otro nivel más profundo, una visión dentro de una visión, un viaje mental dentro de un viaje mental. Dado que viviendo eso sigue teniendo un gran impacto psicológico, emocional y físico sobre Omar, Zerpa le dice que observe y describa la escena como una película para tener más distancia, no involucrarse y tener así un «escudo protector» (Rosa 29). Aquí se subraya la característica de la experiencia onírica como muy intensa, vívida, real. (Gómez Trueba, 1999)

En adelante, Omar escucha una petición del muerto, un mensaje que le pide que le transmita a su mamá: «que no se culpe, que no quiere verla tan triste, [...] “fue un accidente".» (Rosa 29). El hombre se manifiesta a través de una forma visual identificada como parecida a un holograma. Se trata de una 
visión trascendental, de un canal de contacto con la dimensión de los muertos. Esa facultad que posee y ejerce Omar aquí en su vida pasada se considera, como ya mencionamos, «mediumnidad» (Rosa 57). Tiene cierta similitud con la capacidad requerida en su vida presente para comunicarse con el fantasma que es, como se averiguará más tarde, el origen de las pesadillas de Omar, y con eso también de su estado crítico y miserable. La situación del ejercicio de mediumnidad de la encarnación pasada de Omar, que no se especifica concretamente ni en términos del lugar, ni del tiempo, ni de la persona, podría recordar el contexto de los desaparecidos de la dictadura en Argentina en los años 70 y 80 . Una situación similar encontramos en la película Imagining Argentina (Christopher Hampton, 2003) con Antonio Banderas y Emma Thompson. Por lo que se refiere al caso referido, se trata de un accidente de tráfico. El muerto menciona un barranco y después Omar habla de una caída y de un dolor fuerte, agitado de nuevo como si lo viviera él mismo (Rosa 29). El terapeuta decide que basta por ese día, lo relaja, y regresa paulatinamente a la actualidad. Llama la atención que aquí no se usa la palabra "realidad" o la expresión "lo despierta", sino «actualidad», se presenta entonces claramente un viaje en el tiempo.

Se pregunta si Omar se acuerda de lo vivido y esa pregunta se responde de manera afirmativa, lo que indica que no se considera como muy evidente. Efectivamente, parece una característica común en sueños y visiones hipnóticas, tanto reales como ficcionales; muchas veces el recuerdo tiene lagunas y sólo consiste en fragmentos o la persona no se acuerda de nada.

El suspense de la narración se mantiene a través de la alternancia de episodios de tres diferentes tipos: los acontecimientos y desarrollos de la vigilia en cuyo centro se encuentra la relación entre Omar y Paula, los sueños que Omar tiene durante la noche - llamémoslos sueños naturales - y los sueños hipnóticos o «hipnosis regresiva[s]» (Rosa 21).

La segunda hipnosis regresiva se inicia justo después de otra pesadilla cargada de emociones y acontecimientos dolorosos con tal rumbo que Omar no consigue deshacerse fácilmente de su identidad en el sueño ni de otras identidades y personas, como se comenta misteriosamente (Rosa 38f.). Zerpa lo conduce al año 1899 y se cumple su expectativa: tiene la identidad de la misma persona que en la primera hipnosis. Ahora en cambio está por fundar la Sociedad Magnetológica. A las preguntas de Zerpa, Omar sabe dar más informaciones: su anterior Yo nació en Paraguay, pero se encuentra en ese momento en Buenos Aires y nombra su don de ser médium. Eso igualmente se identifica con su 
Nicole HÄFFNER

actividad profesional principal y con el cómo se describe: «fenómenos trascendentales, [...] pasar a otros planos de existencia» (Rosa 40). La reacción del hipnotizador es de satisfacción. Obviamente, se recogieron datos importantes con el fin de llevar a cabo investigaciones e identificar a ese personaje, esa encarnación anterior de Omar; todo ello se dice explícitamente más tarde. Llama la atención que la atmósfera de la novela presenta fenómenos espirituales y parapsicológicos como la hipnosis, la comunicación con almas de personas muertas y los viajes a vidas pasadas como reales, sin que se cuestione la existencia de tales fenómenos. El único personaje que se muestra escéptico es presentado de manera bastante negativa, se trata del novio, exnovio de Paula.

La identidad pasada de Omar se identifica con un tal Ovidio Rebaudi - personaje histórico real, como ya mencionamos - químico y bacteriólogo, fundador de esa Sociedad Magnetológica cuyo nombre cambiaron después a «Instituto Metapsíquico de Buenos Aires» (Rosa 43) y además, miembro honorario de la «Sociedad Científica de Estudios Psíquicos» (Rosa 44).

La tercera sofrosis regresiva se inicia con el objetivo declarado de «empapar la conciencia actual de Omar con la de su vida anterior como médium.» (Rosa 70) La conciencia de Omar, en este caso, se encuentra en medio de una consulta en la que dos jóvenes preguntan por su hermano mayor. La idea de practicar más la mediumnidad funciona: Omar habla con el hermano que le cuenta de su hundimiento durante una excursión de pesca (Rosa 71). El hecho de que está muerto se indica con la falta de solidez de la figura, igual que en la primera sofrosis. Otro elemento común es el mensaje que deja para sus seres queridos vivos a través de Omar/Ovidio: «que los ama, que continúen con el negocio y que el dinero ahorrado está en el sótano del almacén» (cf. Rosa 71). Como en el caso de la mujer y del accidente de su hijo, ese mensaje cumple la función de un afecto consolador y de una motivación a continuar. Además, encontramos un nuevo elemento: una información concreta e importante a través de la que quizá se puede probar la veracidad y validez de la comunicación con el muerto para todos los que no tienen acceso directo a la visión, que son todos salvo Omar y supuestamente la conciencia del propio Ovidio en el pasado. Los hermanos confirman los acontecimientos. La duración de la sesión era de una hora (Rosa 72) pues se supone que se ocupaban de más casos para practicar. El profesor Zerpa comenta el importante logro de haber conectado a Omar con aquella vida pasada.

La próxima y cuarta hipnosis ocurre muy pronto, después de dos páginas. Esta vez, la «nave del tiempo» (Rosa 74) lleva al caso de una mujer cuyo marido falleció de un paro cardíaco y repentinamente 
aparece en pesadillas atormentándola, diciendo que sufría mucho tiempo. «Un paro cardíaco no lo

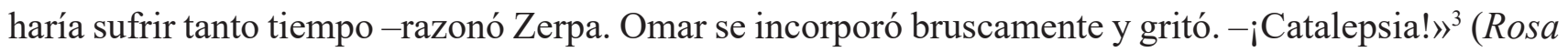
75). La falta de lógica aumenta el suspense así como la reacción brusca de Omar sin saber qué provocó esa catalepsia. Por el uso de este concepto se sugiere que ya no se habla tanto de la perspectiva o conciencia de Omar del siglo XXI, sino más bien del sabio del siglo XIX. Por otro lado, hay que considerar que Omar, a su vez, es enfermero, por lo que no parece inusual que conozca ese término. Poco después, en cambio, Zerpa pregunta quién está hablando y la respuesta es: «Omar, no. Ovidio.» (Rosa 75). Evidentemente, el significado de esa respuesta depende de la manera de cómo se pronuncia y/o enfatiza. Por la coma se diría sin embargo que se expresa aquí una inseguridad, una vacilación. Por el contrario, sin la coma la declaración se entendería como firme, unívoca. En eso se constata una particularidad del idioma español por la coincidencia o polisemia uniendo los dos significados de la negación como sola respuesta o revocación de la enunciación por un lado (en inglés por ejemplo: "no”) y la negación de un verbo por otro lado (en inglés: "not”) - aquí se tendría que repetir «habla» lo que se sobreentendería implícitamente. A través del personaje de Zerpa se pronuncia la idea de que el nombre puede cambiar, pero sin embargo se trata del mismo testigo, sólo que con distintos disfraces. Lo que significaría una correspondencia total de la identidad de Omar y de Ovidio en distintos siglos. Parece interesante destacar que esa parte de una “teoría de viajes oníricos", si la llamamos así, no se da desde la perspectiva interna de la visión y/o un ámbito raro, estrafalario, típico de sueños (naturales), sino que proviene de la mente intelectual, profesional y despierta de un especialista, bueno - de parapsicología.

Como ya se mencionó antes, el tenor de la novela promueve una atmósfera espiritual que presenta fenómenos sobrenaturales o que podrían considerarse imposibles o puramente ficcionales, que constituyen infracciones contra las leyes comunes y aceptadas de la física ${ }^{4}$ con toda naturalidad. Esa manera de presentar fenómenos que se podrían considerar como supra-reales o espirituales, integrados sin escándalo o choque en un contexto realista, sin que los personajes se extrañen, recuerda el concepto literario del realismo mágico, tan importante, frecuente y popular en la literatura de Latinoamérica, al

3 Este tecnicismo quizá los jóvenes lectores no lo conocen. Su definición según el DRAE: «Accidente nervioso repentino, de índole histérica, que suspende las sensaciones e inmoviliza el cuerpo en cualquier postura en que se le coloque.» Real Academia Española (2018). Diccionario de la lengua española. URL: http://dle.rae.es/?id=7toGSuK. Última consulta el 06-08-2018.

4 Una tal infracción contra las leyes de física es una de las características de los sueños literarios que define Stefanie Kreuzer en el nivel del contenido (Kreuzer, 2014, 85). Cf. también Engel, 2017, 21. 
Nicole HÄFFNER

menos a partir del autor colombiano, Premio Nobel, Gabriel García Márquez. En analogía podríamos hablar de un cierto "realismo espiritual" como nuevo concepto, para el que se encuentran más novelas actuales argentinas que lo promueven, sobre todo Jardines del Origen (2014) de Miguel Cantilo. Otro indicio para ese punto de vista lo encontramos ya en la página $17 \mathrm{f}$. de la novela Rosa misma, donde se enfatiza que no sólo se trata de un concepto estético teórico-literario, sino también de una visión del mundo práctica-filosófica: El protagonista profesor Fabio Zerpa declara: «Este nuevo siglo será de espiritualidad o no será [...]. El homo sapiens se tranformará en el homo spiritualis.» (Rosa 17f.) Esta formulación subraya la necesidad urgente de más espiritualidad en relación al sobrepeso de la razón/racionalidad ("sapiens") que se puede constatar desde un cierto punto de vista después del siglo XVIII, el llamado siglo de las luces, en el pensamiento europeo y del occidente, tradiciones por las que los autores y el público argentino se interesaban mucho. Se puede afirmar el papel clave del espacio cultural y literario de Argentina como compartiendo ideas europeas pero también siendo un país latinoamericano con cierta herencia tradicional indígena, aunque en menos medida que en otros países del continente, como Bolivia y Perú. Así, es significativo, y no pura coincidencia, que en la novela los protagonistas viajen a un pueblo indígena cerca del Cuzco en Perú para efectuar un ritual especial y por fin encontrar la solución al problema de base de la narración. De eso se hablará más tarde.

Volvamos a la sofrosis actual. Omar relata que ve la lucha del marido y ahora también se concretan las condiciones y el significado de la catalepsia: «¡lo enterraron vivo!» (Rosa 76) Eso, grita Omar, obviamente con tanta emoción y horror que Zerpa se ve obligado a volverlo al presente rápidamente, lo que logra enseguida.

El efecto benéfico del personaje de Paula se muestra claramente: una sonrisa ilumina la cara de Omar después de ese episodio horroroso, porque tiene una cita con ella (Rosa 76). Siguen hablando sobre las aventuras oníricas de Omar, y Paula está fascinada. Se menciona el deleite de Omar por el hecho de que ella le cree todo lo que cuenta, poniendo el contraste con la mayoría de sus amigos que pensarían que «deliraba» (Rosa 77). Entonces se demuestra que hay mucha gente que no cree en la existencia de tales fenómenos sobrenaturales que se enuncian como reales y verdaderos en la narración. La gente escéptica incluso representaría la mayoría, lo que hace de los que sí creen en eso una minoría iniciada, tal vez privilegiada. Se encuentra una posible conexión con el grupo de gente que cree en la veracidad de los sueños y el grupo de los viajeros en general, que quizá comparten un 
conocimiento y una actitud común que los distingue de gente que no viaja.

Poco después hay un episodio en el que los expertos Zerpa y Nigro analizan la última sesión de hipnosis mediante una grabación de vídeo (Rosa 79). Llegan a la conclusión de que Omar mismo había analizado los hechos del pasado con sus conocimientos actuales del siglo XXI, lo que explica el uso del concepto de "catalepsia”. «Eso demostraba que se había producido la conexión de conciencias fuera del tiempo y del espacio.» (Rosa 79), y esto se considera un gran avance. No sólo la conciencia de Ovidio domina en el pasado, sino que también Omar aporta algo de su conciencia a la de su encarnación pasada.

Un tema actual e importante de la juventud del siglo XXI y del público destinatario de la novela se aborda a continuación: la omnipresencia y los peligros de las llamadas redes sociales. Estos hechos contienen una función didáctica pues se promueve una toma de conciencia de tales riesgos para que los jóvenes vean que puede tener consecuencias graves difíciles de borrar.

Sin introducción extensa sigue la próxima y quinta sesión de hipnosis regresiva. El entorno se describe como un despacho y Rebaudi está organizando la redacción del semanario del Instituto Metapsíquico de Buenos Aires (Rosa 84). Rebaudi manda salir a todos y dice que lo espían. Siente una presencia y pregunta: «¿quién está aquí?». Eso representa otro elemento notable: el poder sentir una presencia sin verla se presenta como un hecho, a la manera del realismo espiritual, como ya se ha explicado. Enseguida se añade otro elemento: la comunicación mediante pensamientos, la llamada telepatía (Rosa 84). Y tampoco el personaje del pasado manifiesta ninguna desconfianza o escepticismo, cuando Omar se presenta como su próxima encarnación. Dice que siente «una enorme empatía» (Rosa 85) y se interesa por la práctica de la sofrología, que hizo llegar a Omar. Incluso cuenta un repetido sueño que tuvo en las tres noches anteriores en el que alguien del futuro lo visitaría, lo que se revela entonces como un sueño profético. Zerpa habla de «precognición» (Rosa 85). Sorprendentemente, se relata que esa palabra murmurada llega a los oídos de Rebaudi que pregunta por la procedencia de esa voz (Rosa 85). Ese viaje onírico al pasado no pertenece únicamente al hipnotizado, sino que también el hipnotizador puede comunicarse directamente con la persona en el pasado. Hasta tal punto llega el poder de la telepatía en el concepto de la novela. Zerpa informa a Rebaudi y al lector que tal comunicación se considera un «fenómeno parapsíquico» (Rosa 85). En relación con la explicación de la «precognición» como «conocimiento previo de un hecho futuro» (Rosa 85), el hombre del pasado 
expresa su agrado y entusiasmo por el hecho - percibido por él - de que en el futuro esos fenómenos se tomen con naturalidad (Rosa 85). Eso implica claramente una interpretación, por parte del hombre del pasado, de un desarrollo deseable que todavía hacía falta en su epóca, y que, por otro lado, Zerpa identifica como todavía bien lejos de terminado: «[A]ún hay mucha gente que descree.» (Rosa 86)

Se tematiza el conflicto entre lo que puede ser la parapsicología y/o mediumnidad y la iglesia católica. Rebaudi fue expulsado de su país, Paraguay, por parte del Vaticano y éste incluso mandó a un espía, un tal Pedro Villafañe. Aceptando la teoría de que en el subconsciente de Omar «está activo ese canal de comunicación con los espíritus» (Rosa 86), Rebaudi explica que cualquier espíritu, es decir difunto, «que no haya conseguido su evolución» (Rosa 86) puede encontrar ese canal. Eso significa un gran paso en el proyecto de resolver el enigma de los sueños de Omar, porque da la información del fantasma que lo obsesiona, se trata del espíritu de una persona muerta que por alguna razón no logra deshacerse de este mundo y que posiblemente trata de buscar ayuda en Omar. Entonces, durante esa aventura onírica, se transmiten del pasado al presente conocimientos importantes y también, como se verá más tarde, del presente al pasado. Zerpa ayuda a Rebaudi en el caso de un ovni y unos extraterrestres y le explican que hay necesidad histórica de que descubra la fiebre amarilla y ponga a una ciudad en cuarentena.

En el episodio siguiente la aventura onírica adquiere dimensiones más grandes; al despertar, Omar habla con una voz distinta y se comenta que «el alma reflejada» (Rosa 87) no es la de Omar. No conoce el ascensor, lo llama «cubo volador» (Rosa 88), ni los autos ni el celular («iSu saco está sonando!» Rosa 88). Por esos indicios Zerpa llega a la conclusión de que no se trata de Omar sino del espía Pedro Villafañe pues se ha producido una posesión. Zerpa logra encerrar al cuerpo de Omar con el espíritu del espía. Entonces ese espíritu logró traspasar los bordes entre los ámbitos del sueño hipnótico que equivale al pasado, y la realidad de la vigilia que está situada en el presente. Significa que los límites se hicieron transparentes o borrosos. En lugar de un viaje al pasado, un espíritu del pasado logró viajar al presente dentro de la conciencia y del cuerpo del soñador. Se podría entonces considerar un caso especial.

Con la ayuda de un sacerdote que cree en la existencia de vidas anteriores logran hacer un exorcismo y librar a Omar del espíritu maligno. Siguen las aventuras oníricas, pero en este caso es la protagonista Paula quien emprende su primera hipnosis regresiva. El objetivo es averiguar si estaba relacionada con 
Omar en su vida pasada, ya que según el concepto presentado «las almas siempre regresan y tratan de volver a encontrarse aunque cumplan distintos roles» (Rosa 108). En el caso afirmativo de una relación, este viaje también tendría la función de confirmar que es probable que fuera su destino ser la pareja de Omar (Rosa 109). Además, cabe la posibilidad de que se pueda encontrar alguna clave sobre el espíritu que desea comunicarse (Rosa 109). Pero nada de eso acontece. Como es habitual en ese género de hipnosis, la hipnotizada habla y describe lo que ve. Pero para la sorpresa del lector no se trata de un entorno habitual y similar a las condiciones de los viajes al pasado que hizo Omar a la vida de Ovidio Rebaudi. Más bien se describe un entorno mágico, fuera del mundo de la realidad cotidiana: Paula se encuentra flotando protegida en una esfera radiante (Rosa 109 f.). La atmósfera se determina como de mucha paz, bienestar, brillo y seres de bondad entre los que se nombran los abuelos de Paula. Este entorno ya destaca por elementos típicos de sueños: una noción imprecisa de tiempo y espacio, elementos extraños sin explicación, infracciones de las leyes naturales. Con todo ello, se describe un ambiente onírico, se diferencia mucho de los anteriores que experimentó el lector desde la perspectiva del protagonista Oma; tenía características reales, por ejemplo la oficina histórica de Rebaudi. Una clave para la explicación de esa diferencia se encuentra en la presencia mencionada de los abuelos de Paula. Se puede suponer que están muertos y que consecuentemente Paula se encuentra en la dimensión de las almas, entre dos existencias, el mundo real o terrestre, lo que se confirma explícitamente en lo que dice la figura de Zerpa al despertar de Paula: «[H]ubo un “entre vidas” en 1899 para vos, tu alma seguía aguardando la espera, en aquello que llamo mar de la serenidad.» (Rosa 110 f.) Así se introduce la novela, de paso a través de un caso especial, de un viaje al pasado, un concepto de lo que viene después de la muerte. En concordancia con la idea de vidas pasadas se trata de un concepto espiritual circular de renacimientos como lo representan las religiones del budhismo e hinduismo. Ese concepto no sólo se sostiene teóricamente en un discurso, sino también se demuestra con validez a través de la prueba de ese viaje onírico que se efectuó.

A continuación, se describe la sexta hipnosis regresiva de Omar que empieza con una conversación con Rebaudi en el pasado (Rosa $122 \mathrm{ff}$.). Se habla sobre el anillo imantado de Rebaudi que ayuda a sacar informaciones sobre los espíritus y conciencias que se acercan (Rosa 122). Le sigue un episodio que supera otra vez a los otros viajes oníricos en extrañeza. Rebaudi pide ayuda a Zerpa y describe el caso de una joven pareja en el que aparecieron en una luz dos seres fuera de rango humano (Rosa 
123). Los seres comunicaron a Rebaudi que no lo necesitaban y luego se despertó en su escritorio dos minutos después de haberse ido a ver a la pareja. Esas informaciones fragmentarias cumplen la función de aumentar el suspense e intrigar al joven lector para descubrir ese nuevo secreto que incluso en ese mundo de telepatía y viajes oníricos al pasado parece extraordinario. Pero primero, y también para prolongar el desarrollo y desenlace de la acción, se cambia a otro tema: Rebaudi dice necesitar los conocimientos médicos modernos de Omar en el caso del fallecimiento inexplicado de un pasajero de un transatlántico de Europa (Rosa 124). Por haber leído la biografía histórica de Rebaudi, Zerpa sabe que se trata de la fiebre amarilla y Omar da las instrucciones del aislamiento urgente para evitar una plaga. Aquí se encuentra una paradoja bastante típica cuando se trata de viajes al pasado: desde el punto de vista del futuro se efectúa una acción o se da una información en el pasado necesarias para que pueda acontecer algo en el pasado, de lo que ya se sabe en el presente lo que pasó. Así que también en el pasado de los seres provenientes del futuro tiene que haber pasado una vez lo que ahora están efectuando. Dinámicas similares se encuentran por ejemplo en las novelas y películas de Harry Potter and the Prisoner of Azkaban (Joanne K. Rowling 1999, Alfonso Cuarón 2004), Time Line (Michael Crichton 1999, Richard Donner 2003) y de manera un poco diferente en la serie Netflix Timeless (Eric Kripke/Shawn Ryan 2016-2018) y en otras obras de ciencia ficción como la película Back to the Future (Robert Zemeckis 1985).

Más adelante, en una sesión en el presente, tratan de invocar al espíritu pero resulta que no funciona, Omar no consiguió la mediumnidad (Rosa 132f.). Sigue la séptima sofrosis regresiva en la que Rebaudi mediante indicaciones en clave le comunica que vaya a la casa de la pareja donde había acontecido el incidente con las presencias indeterminables (Rosa 134). Aquí también se nota la realidad concreta de esa visión porque Omar es incluso capaz de actuar físicamente y abrir una caja. A pesar de que el camino a caballo hacia la casa se había definido como de dos horas, Omar llega en segundos, lo que se explica con una observación de Omar acerca de una estructura de tiempo muy particular y diferente del mundo del presente, fuera de su visión: «Acá el tiempo flota, no es dinámico ni continuo.» Eso concuerda con la frecuente constatación de un flujo de tiempo distinto, una lógica propia o bien también saltos de tiempo y espacio o transformaciones repentinas del entorno en sueños (Solte-Gresser, 2011). Rebaudi, que está con la pareja en la cocina, reconoce la presencia de Omar y le comunica que se acerque. Cuando aparece la luz y se esperan los seres conectados con esa luz, se vuelve a enfatizar 
el rol pasivo y protegido de Omar, su presencia indirecta en esa dimensión que se compara con el espectador de una película y un ser flotando invisible. Se le pide a Omar que mantenga una actitud tranquila: «Zerpa le pide a Omar que permanezca ajeno, como si viese una película, lo tranquiliza diciéndole que nadie puede verlo [...]. Omar estaba en el lugar solo de forma etérea, simplemente debía observar. Podía entender lo que ocurría, se comunicaba de modo telepático.» (Rosa 135)

A esta altura de la novela se juntan dos medios de comunicación en la narración: a través de telepatía llegan palabras a la conciencia de Omar que él enseguida pronuncia textualmente a Zerpa. En ese monólogo, los seres presentan sus actividades e intenciones y su metafísica del universo que se marca como la verdadera:

\footnotetext{
Venimos para protegerlos. Este es nuestro modo de presentarnos y contactarnos con ustedes. Lo estamos haciendo desde hace milenios. Llegará el día en que nos relacionaremos en forma masiva. Sabemos que el miedo los paraliza, por eso dormiremos a la pareja. Usted es un precursor de la nueva era que abrigará al planeta. Su apertura mental nos permite este diálogo. [...] Sabemos de la presencia de Omar. Los multiuniversos que atravesamos, las capas dimensionales, los distintos planos de conciencia... son pantallas de vibración que nos componen; lo que los terrícolas llaman infinito se cierra en sí mismo. El caos que ven ustedes, no es tal, pues su lineamiento final se convierte en el verdadero orden que nos rige. El todo sabe que la entelequia debe abarcar a cualquier ente que lo compone. Omar nos observa desde el sitio que la relatividad del tiempo y del espacio se lo permite. [...] [N]uestra tecnología es muy compleja y si bien ustedes han dado los primeros pasos, aún les queda mucho por comprender. Nuestro principal propósito es protegerlos de su propia violencia, de su incomprensible autodestrucción. (Rosa 135ff.)
}

Primero se manifiesta una intención benévola y protectora, disipando - al menos en la medida de que el/la recipiente y los protagonistas quieran creer en la honestidad de esa enunciación - la idea de una posible amenaza. La actividad cubierta de esos seres ya existe desde hace milenios y se pronostica un futuro en el que la comunicación se efectuará manifiestamente. Rebaudi con su espiritualismo es definido como precursor de esa nueva era cuya llegada se presenta como segura. La creencia humana según la cual el universo sea infinito y caótico se desenmascara como engañosa y falsa en beneficio de una verdad de un orden integral/universal ${ }^{5}$. Se menciona una tecnología muy avanzada y superior a la de los humanos. Con eso se incluyen los aspectos de las ciencias (naturales) y de la técnica que muchas veces se oponen o se ponen en contraste con el espiritualismo. Esa evocación puede tener la función de dar mayor fundamento y credibilidad a esa revelación de una verdad distinta de la que comúnmente

5 La revelación de "grandes verdades filosóficas, religiosas, morales o, incluso, científicas” determina también (Gómez Trueba, 1999, p. 13) como una característica muy frecuente en sueños literarios. También se habla del sueño como "un despertar a la verdad" (p. 56).) 
Nicole HÄFFNER

se cree. Los seres llegan a viajar por tiempo y espacio y también a percibir y comunicar directamente pensamientos a Fabio Zerpa en el futuro (Rosa 137). Al final del discurso se retoma la primera frase y el aspecto de la actividad protectora especificándose de qué hay que proteger a los seres terrestres: de sí mismos, de "su incomprensible autodestrucción”. En esta afirmación se puede detectar una crítica al ser humano y a su llamado desarrollo de la civilización desde una perspectiva externa.

Este episodio tiene pocas conexiones con la trama principal de la novela y por lo tanto se puede identificar como una digresión, una intercalación. Para una novela juvenil se encuentran bastantes elementos complejos y de reflexión sobre distintas dimensiones, nociones como tiempo, espacio, existencia y humanidad. Palabras y conceptos como «entelequia» son ajenos a (no excluvisamente) jóvenes lectores de hoy día e invitan a la investigación en internet, ahora ampliamente accesible en las nuevas sociedades de la información y las nuevas tecnologías. Así se implica también una intención didáctica, incitando a los lectores a informarse y a reflexionar.

En la progresión de la novela, se muestran claramente marcados como extraterrestres los seres manifestando su intencionalidad al elegir a Fabio Zerpa, ellos le muestran su razón y su objetivo que se identifica como logrado:

para que la gente tome conciencia de nuestra existencia. No necesitábamos un científico, porque lo que saben nos resulta insuficiente, necesitábamos coraje. Cuando usted volaba en ese avión francés Morane-Saulnier, junto al capitán Alexis de Nogaetz de la Fuerza Aérea, decidimos hacernos ver entrando en la octava de colores que captan sus ojos, así logramos mediante su labor establecer un paradigma donde hasta un niño pueda hablar de ovnis sin causarle el pánico que tenía su gente a mediados del siglo XX. (Rosa 137)

Se describe el ambiente de la espera de una nueva era que ya empezó y en la que, contrariamente tal vez a lo que (todavía) piensa el lector, sería normal hablar de ovnis en serio. La evocación de un incidente en el pasado biográfico de Zerpa es un recurso narrativo que logra dar cohesión a la actividad de los extraterrestres y ofrece con sus datos exactos la impresión de una referencia real, lo que provoca mayor crédito aún a lo que relatan los seres. Y efectivamente, investigando sobre la persona real de Fabio Zerpa y sus publicaciones, se encuentra la descripción del episodio de cuando vio un ovni en su libro actual Señales en el cielo: Lo que nunca se contó. Ovnis, telepatía, mundos subterráneos y profecías (2017). eBook: Sudamericana. Con eso se conecta de nuevo el mundo ficcional de la novela con el mundo real y se produce un mayor énfasis en el cambio necesario hacia cierto espiritualismo. Un proyecto, por cierto, que La Eternidad de la Rosa comparte con la ya mencionada compleja novela 
épica, mítica y metafísica de alto estilo de Miguel Cantilo del año 2014 con el título Jardines del Origen. Esto parece interesante en cuanto al ya explicado posible nuevo paradigma de la literatura argentina que se podría llamar "realismo espiritual" que investigo y analizo en profundidad en mi tesis de doctorado.

En la progresión de la historia de La Eternidad de la Rosa se sigue con la desaparición de los seres extraños y con la pareja adormecida a través de las paredes, otra infracción a las leyes naturales; se describe la imagen de un ovni y la subida de las figuras en un túnel de luz (Rosa 137), lo que parece de una película de ciencia ficción.

En cuanto a la pareja, Zerpa explica que los extraterrestres los estudiarán y después de poco tiempo los devolverán sin que puedan recordar lo que pasó (Rosa 138). Pero sí tendrán «algunos flashes muy vagos, generalmente en sueños.» (Rosa 138) Aquí reaparecen los sueños, en este caso sueños no inducidos, espontáneos, en su función de volver a traer experiencias vividas de vuelta a la conciencia desde un subconsciente profundo al que no tenemos acceso en estado de vigilia. Dicho concepto es común igualmente en el contexto del psicoanálisis y se encuentra en la base de las teorías de los traumas ${ }^{6}$.

El capítulo termina con una reflexión de Zerpa que al mismo tiempo es un mensaje para el lector: «Ahora [...] con la sofrosis cuántica se introducía un nuevo paradigma: se confirma la existencia de vidas anteriores, de entidades multidimensionales. Se confirma la eternidad del ser.» (Rosa 139) Esta constatación representa un resumen de lo ocurrido en ese capítulo y asimismo de los mecanismos de toda la novela, se insiste en el carácter real y probado de esos fenómenos sobrenaturales que dentro y fuera de la realidad ficcional de la novela (todavía) se ven confrontados con cierto escepticismo.

Un resumen del efecto de las sofrosis sobre Omar se explicita al afirmar que se siente «eufórico» (Rosa 142). «Los viajes al pasado le otorgaban estados amplificados de conciencia con aventuras inéditas que lo emocionaban. Toda la atención que le brindaban en la Fundación lo hacía sentirse protagonista, valioso y cuidado.» (Rosa 142). Se subraya entonces el carácter emocional, emocionante y enriquecedor de esas aventuras espirituales. Por otro lado, vivir eso se transformó de un horror de pesadillas al principio de la historia a ser un privilegio que hace sentirse importante a la persona entera que lo vive.

Otro mecanismo narrativo de revaloración de la novela se pone de manifiesto cuando encontraron a una mujer de los sueños naturales de Omar - descubriendo que se trata de un acontecimiento real -, Zerpa la llama y ella susurra: «estoy hablando con el famoso de los ovnis» (Rosa 144), lo que enfatiza 6 Cf. por ejemplo Freud, 1899/1900; Barrett, 1996. 
Nicole HÄFFNER

la mayor credibilidad y el respeto que se otorga a Zerpa y sus investigaciones en Argentina, según como se presenta en la novela. Incluso se habla de una canción de un tal Andrés Calamaro con el título «Fabio Zerpa tiene razón» (Rosa 144). Efectivamente, se trata de una canción de Rock ya del año 1984 que habla sobre marcianos en la tierra.

En la octava regresión se relata otra visita a la casa, con la pareja de vuelta (Rosa 144f.). De nuevo, en términos profesionales, se habla de la «frenología [...] modificada» (Rosa 145) de la pareja, lo que a través de la reacción impulsiva de Rebaudi - «¡Eso es un ultraje a nuestra raza!» (Rosa 145), introduce otros aspectos tales como el de poder, superioridad y jerarquía. Se pregunta indirectamente con qué derecho o justificación alguien podría ejercer un tal poder. Zerpa, por otro lado, lo calma y destaca la posterior normalidad y los fines benéficos (Rosa 146).

Llegan de nuevo los extraterrestres con un mensaje más preciso sobre los planes y necesidades del futuro de la humanidad y sostienen que tiene que haber una evolución a su debido tiempo, pero para despertar sus capacidades adormecidas los humanos tienen que controlar su agresividad. No debería existir «esa maldad entre hermanos» (Rosa 146). Estos aspectos enlazan con ideas comunes sobre capacidades inexploradas del cerebro humano; por ejemplo, se tematiza en el contexto de una poética del conocimiento en películas como Lucy (Luc Besson, 2014). Además, se menciona un problema principal filosófico y teológico: el problema del mal en el mundo y la maldad humana, cuyas características y procedencia se plantean en diversas teorías y obras literarias, por ejemplo de Jean-Jacques Rousseau, de Thomas Hobbes y de Pierre de Marivaux. Este tema parece más actual que nunca también en el mundo contemporáneo en el que sigue habiendo conflictos y guerras entre países, ideologías, culturas y religiones. En ese sentido, esta novela y la literatura en general puede transmitir ciertos conocimientos sobre cómo vivir y convivir en general y especialmente en el mundo globalizado del siglo XXI, como lo subraya Ottmar Ette (2012) en sus ideas teóricas. Como conexión con la historia del mundo extra-ficcional se nombran personas potenciales que habrán poseído esas facultades desarrolladas: Hermes Trismegisto y Jesucristo (Rosa 146). Se habla del concepto filósofico chino de la dualidad del yin y yang (Rosa 147). Los seres dicen que su propio inconsciente es similar al de los humanos, pero "más sútil y [pueden] accede[r] a él con total facilidad" (Rosa 147). También se habla de la tecnología de la antimateria que revolucionaría o revolucionará todo el ámbito de la energía (Rosa 147f.). Muestran una parte de su tecnología medicinal en forma de un dispositivo que hace visible la 
totalidad del cuerpo humano en un tipo de tomografía (Rosa 148f.).

Después de más de 20 páginas viene la hipnosis regresiva número 9 (Rosa 172ff.). Ya se anuncia a modo de prolepsis que es posiblemente el último contacto con Rebaudi (Rosa 172). De vuelta en el año 1899, Omar y así también indirectamente Zerpa son testigos de una conversación entre Rebaudi y una mujer con el nombre de Elvira que le agradece su ayuda, le regala una rosa y le comunica sus sentimientos amorosos (Rosa 172f.). Omar observa que también en su conciencia actual le parece que conoce a la mujer y se emociona (Rosa 172). En una conversación entre los expertos Fabio Zerpa y Norma Nigro se evoca el tema de una posible progresión hipnótica para ver el futuro (Rosa 176f.). Con ello se aborda otra discusión filosófica bastante común, la de si es bueno o no saber lo que pasará en el futuro. Ese tema se encuentra ya en la Antigüedad romana, por ejemplo en la famosa Oda CarpeDiem de Horacio $^{7}$ y hasta en la canción popular «Que será, será» (Original Jay Livingston/Ray Evans 1956, varios cantantes como Doris Day y José Feliciano o también la Hermes House Band). Y en concordancia con la respuesta más frecuente, igualmente Zerpa declara, también por experiencia: «Tu idea es buena, pero, sucede que una vez lo hice con un gran amigo y vio lo que no tenía que ver.» (Rosa 177) Y Nigro acepta ese rechazo razonable. Entonces, este es otro ejemplo de cómo esta novela juvenil incluye hábilmente temas y reflexiones filosóficas como de paso, sin presentar monólogos largos e inapropiados para este género y el público destinatario.

En la décima hipnosis regresiva se describe el viaje a otra vida anterior de Omar en el año 1600 (Rosa 178-183). Efectivamente, se reconoce, es un joven en un ritual de iniciación. La temática espiritual y de avance de la humanidad igual reina aquí, se habla de «transformaciones [...] [de] la sociedad», «doctrinas místicas» (las dos Rosa 179). Se encuentran indicaciones como el nombre de esa encarnación - Nicolae -, el nombre de un médico, el idioma alemán y el símbolo de una cruz con una rosa que ayudan a ubicar ese episodio en la historia. Además, hay que reconocer que las vidas pasadas pueden haberse desarrollado en una sociedad y en un punto geográfico totalmente distintos de la vida actual. El episodio onírico sigue con la mañana siguiente, padre e hijo deben salir a una expedición secreta (Rosa 180). Adelantándose, Omar se encuentra en un campo de excavaciones buscando una

7 Cf. Horatius Flaccus, Quintus (siglo I a. C.): Carmina I,11.: «Tu ne quaesieris, scire nefas, quem mihi, quem tibi | finem di dederint, Leuconoe, nec Babylonios | temptaris numeros. Ut melius, quidquid erit, pati.», Tú no preguntes, porque no se debe saber, qué fin me dieron los Dioses a mí, qué a ti, Leuconoe, y no consultes los números babilónicos [= horóscopo]. Cuánto mejor es soportar lo que venga.' (traducción propia:N.H.) 
tumba, la de un sabio germánico del siglo XV. El protagonista describe el proceso de apertura de un ataúd de piedra, se descubre una lámpara encendida (!) y se escuchan cantos (Rosa 181). Omar se pone a orar con las otras personas y siente una enorme emoción. A causa de una convulsión del Omar hipnotizado en el siglo XXI en ese punto terminan la hipnosis y lo regresan (Rosa 181). El episodio se caracteriza como «iOtra aventura fascinante!» (Rosa 181) y se comenta que «la realidad supera la ficción» (Rosa 182). Enseguida se efectúa el análisis del episodio con la ayuda de la biblioteca. Se habla del rosicrucianismo, se menciona la francmasonería y se explican los símbolos: la cruz y la rosa, sabiduría y pureza, Divina Energía masculina y sustancia primordial femenina que juntos dieron origen al universo (Rosa 182). La tumba era del fundador Christian Rosenkreutz. A su padre Frank, en aquella vida, lo identifica Omar, por la sensación que tenía, con el espíritu que lo acosa en el siglo XXI (Rosa 182f.). En el relato, se subraya de nuevo la importancia y el carácter real y auténtico de las ideas espirituales de la novela conectándolas más con el pasado histórico otra vez entrelazando ficción y realidad, visión onírica del pasado y presente tanto de los protagonistas como del lector del siglo XXI. Además, se revelan aspectos de los conocimientos sobre el espíritu que habrá sido conectado de manera cercana con Omar ya en otras vidas. Por lo tanto, la aventura onírica otra vez cumple la función de un acceso privilegiado a informaciones que servirán para resolver el conflicto principal de la obra (Gómez Trueba, 1999, p. 14).

La historia sigue con otra hipnosis regresiva, ya la undécima, en la que se avanza aún más atrás, al año 1540 (Rosa 185ff.). Siguiendo la concepción estructural de la novela, dialógicamente y progresivamente, se aportan informaciones sobre el escenario y la identidad a través de las preguntas de Zerpa y las respuestas de Omar. En esa encarnación es un sultán hablando en turco sobre estrategias de una batalla y luego leyendo poesía (Rosa 186). Después de una escena horrorosa de plena guerra la narración salta a la muerte del mejor amigo y luego del sultán mismo. Omar percibe cómo sale el alma y se dirige hacia una luz brillante con el sentimiento de una paz absoluta (Rosa 187f.). De nuevo, Omar reconoce el espíritu del siglo XXI en esa vida pasada, concretamente en el mejor amigo, cuyo nombre se traduce como «el padre de las rosas» (Rosa 189). Aparece la figura de Elvira, la enamorada de Rebaudi, de la que el lector podría pensar que se trata de la vida anterior de Paula pues se identifica con el espíritu que pide ayuda a Omar en la actualidad del siglo XXI (Rosa 190). El símbolo de la rosa se identifica con el amor universal que puede variar (Rosa 190). 
Posteriormente, se prepara el clímax tanto de las aventuras oníricas como de la trama de la novela misma: se planifica un ritual con el brebaje llamado «ayahuasca» (Rosa 191) que produce visiones. Zerpa explica que se tratará de «un estado amplificado de conciencia, similar a la sofrosis. Él [scil. Omar] siempre estará consciente. Es una llave para el conocimiento de uno mismo y el camino para la sanación.» (Rosa 192) Con esas palabras y también con la experiencia propia se disipan la mayoría de las dudas y del escepticismo manifestados por Omar y Nigro, lo que se puede relacionar con una actitud probable del lector y una función convincente también en ese nivel extraficcional. Investigando sobre el tema, se aprecia que de hecho la experiencia con la ayahuasca es bastante popular entre (jóvenes) viajeros del mundo que llegan a Perú. Las experiencias se cuentan y se discuten en blogs en internet (Cf. por ejemplo H., 2016; Creighton, 2014; Lazzarino, 2011; Anónimo (apodo Guancheman), 2010), lo que se puede tomar como simple índice de un cierto interés público, al menos en cierto grupo de la sociedad abierto a tales experiencias espirituales. Además, un ejemplo para una obra artística que aborda el tema de las visiones de ayahuasca es la colección de cuadros colorados de Pablo Amaringo con el título Ayahuasca Visions: The Religious Iconography of a Peruvian Shaman que se hizo con la colaboración del antropólogo Luis Eduardo Luna (Cf. Amaringo y Luna, 1999).

Para el ritual mencionado, los tres personajes viajan a Lima y de ahí al Valle Sagrado, donde se encuentran con un brujo (Rosa 193). Omar tiene que pasar un tiempo aislado. El brujo le da la ayahuasca, subraya la importancia de confianza y serenidad por parte de Omar y para ello toca melodías de sanación y cantos incaicos en una ocarina (Rosa 195). El día después todos emprenden el viaje hacia un lugar especial a una altura de 4000 metros llamado el «Gran Portal» (Rosa 194), donde se desarrollará el ritual mismo. Durante el viaje, Omar cuenta sueños colorados y recuerdos «desde que se creó [...] [su] alma» (Rosa 198). Habla de tres sueños. En uno viajó al tiempo de la Segunda Guerra Mundial a un aviador en pleno combate que muere con sus emociones enfocándose en la cara de su hija (Rosa 199). En el segundo vio a dos hermanos refugiados en una cabaña bloqueada por una tormenta de nieve. Uno de los hermanos estaba enfermo y murió en una agonía terrible (Rosa 199). En el último vio la vida de una mujer infeliz en la época renacentista que su familia había mandado a un convento para que no se casara con un joven de una familia en conflicto con la suya (Rosa 200). Aquí, finalmente, se confirma que también Omar y Paula estaban conectados siempre, porque Zerpa reconoce en esos escenarios vidas pasadas de Paula que descubrió en sofrosis con ella aunque no se 
relataron en la narración. Con la cercanía del lago Titicaca se da otra referencia para ubicar los eventos ficcionales en un ámbito real. Se insiste en que ciertas cosas superan lo que pueden saber o explicar las ciencias: Zerpa afirma: «[D]esorienta a cualquier investigador, incluyéndome. Nadie sabe quién construyó la puerta ni para qué.» (Rosa 202) Con la evocación del sahaswara, el chacra coronal, de nuevo el lector es invitado a investigar y se conecta la mitología incaica con tradiciones de la India a un cierto espiritualismo universal. Se habla del Portal como posible «puerta dimensional» (Rosa 203). En la preparación de Omar se explica lo que acontecerá: «Se presentarán ante ti realidades paralelas originadas en las decisiones que has hecho en distintos momentos de tu vida. Hoy debes elegir la correcta.» (Rosa 203) En eso lo guiará su intuición y luego «el Espíritu Superior» (Rosa 204).

Lo vivido por Omar en el ritual se cuenta desde la retrospectiva: se concentró en la época del comienzo de sus pesadillas. Una sensación de «livianidad» (Rosa 205) le invadió y ve diferentes túneles que representan realidades paralelas, alternativas. En el primer túnel un enfermo que cuidaba mucho pudo salir del hospital y en esa realidad se vio más tarde casado con la hermana de su amigo Daniel (Rosa 206). Entonces, se dio cuenta de que esa no era su realiad actual sin Zerpa y Paula, volvió atrás y buscó otro túnel. En el desarrollo alternativo el paciente que había cuidado falleció. Y en esa noche empezaron las pesadillas, como pasó en la realidad que había pasado Omar antes de buscar ayuda por parte de Zerpa. Pero en esa realidad no siguió la recomendación de su amigo Daniel y no fue a buscar a Zerpa. Su vida se convirtió en un suplicio y sufría mucho por las pesadillas. Se nota entonces que otra vez esa variante no corresponde a su vida actual. Otra vuelta para atrás. Después, se describe la aparición de un ser que irradia amor y paz y que tiene que ser el Maestro Ascendido del que le habían hablado en la preparación al ritual. Sensaciones y recuerdos confluían en Omar y el ser le dio el permiso para efectuar su tarea (Rosa 207). El lugar de esos acontecimientos se identifica por Zerpa con el akasha, el lugar de infinidad de los sabios hindúes y la leve sensación como de un cóndor se explica como símbolo de la conciencia en los pueblos sudamericanos (Rosa 207). De nuevo se representan relaciones entre diferentes filosofías de diferentes lugares geográficos de la tierra y se unen a un concepto espiritual común y universal. Omar cuenta que vio entonces un paisaje natural con praderas, lagos y montañas, donde vio el felino, la figura que ya antes se identificó con el espíritu en

8 La palabra «livianidad» (Rosa 205), por el contexto, («sentí que todo lo material desaparecía» Rosa 205) se debería entender en la variedad lingüística del español argentino como un sentirse ligero, es decir, sin peso y no en el sentido de frivolidad. 
busca de ayuda (Rosa 207). Omar determina el momento decisivo: «Nos fundimos en un abrazo y nos entendimos.» (Rosa 208). Seguidamente, el texto refiere el diálogo de los dos en discurso directo. Se explica que las emociones que originaba el espíritu en otra gente no lo dejaban irse en paz, pero que ahora Omar le liberó el camino (cf. Rosa 208). Además, se explica que intervino para unir a Omar con su verdadero amor en esta existencia, Paula. El diálogo se termina con la prolepsis de un último favor que Omar le hará al espíritu en la próxima noche (Rosa 208). Se resolvió el enigma de la identidad entonces para el protagonista pero todavía no para el lector y se añade el elemento indeterminado de lo que ocurriría en esa noche, lo que mantiene el suspense. El funcionamiento de ese Portal ahora se pone en paralelo con la vida en la explicación de un indígena: «La puerta de Aramu Muru funciona como la vida [...]: fabricamos la realidad a partir de nuestros pensamientos y decisiones, mientras que el futuro tal cual lo percibimos ya existe... la única verdad es el eterno presente.» (Rosa 208f.) Ese comentario continúa el tenor de reflexiones espirituales y filosóficas de la novela y parece bien complejo para el género juvenil. Expone el concepto de que la realidad se construye y siempre es subjetiva desde un punto de vista determinista.

El último sueño que el espíritu en la visión ya había anunciado se relata a la mañana siguiente por Omar también en retrospectiva (Rosa 210f.). Le apareció la última encarnación del espíritu que tiene que equivaler al paciente que se había mencionado y se enfatiza en su voz maravillosa (Rosa 210). El espíritu se declara feliz y agradecido y deja a ese personaje a las rosas y a la gente, «y en las noches de pasión sientan que siempre habrá alguien más que las abraza, las estruja y las besa» (Rosa 211). La última palabra del capítulo desvela la identidad del espíritu con el nombre concreto: «Sandro» (Rosa 211). Por la posición destacada de esa revelación concluye la curva de suspense que había aumentado más y más por la falta de explicación; se entiende que el lector debería saber quién es Sandro. Aquí, a pesar de todos los elementos de filosofía universal y de asuntos humanos en general encontramos de nuevo un personaje famoso y real de la cultura argentina: Sandro es un cantante muy famoso que en realidad falleció en el año 2008 y cantaba una canción que se llama «Rosa, Rosa» (lanzamiento 1969). Entonces, repentinamente, se explica todo, las emociones de la gente con su música que lo atan al mundo de los vivos, también el símbolo de la rosa que había conectado todos los relatos de vidas pasadas e igualmente se encuentra en el título de la novela. Ahora se entiende también a qué se refiere tanto el texto de portada con que la novela «rinde tributo a uno de los más grandes artistas populares 
argentinos» como el autor Gabriel Moschitta en su introducción con «un hecho que me impactó como a gran parte de los argentinos y a tantos latinoamericanos» (Rosa 7). Un lector europeo o de otro continente tal vez se quede sin entender el gran descubrimiento y se sienta impulsado a investigarlo.

Sigue un último capítulo en la novela, titulado epílogo. Se narra el regreso a la Argentina, el encuentro feliz con Paula y algunas reflexiones sobre las conexiones de los indicios como el rol de la música (cf. Rosa 213f.). También se explica que, ya en una canción, Sandro se había identificado con un felino, en concreto un puma (Rosa 216). La canción se llama «Mi amigo el puma» (Rosa 216).

Para concluir se puede decir que paso a paso las numerosas aventuras y viajes oníricos a existencias anteriores que el protagonista Omar junto con sus terapeutas Zerpa y Nigro y la joven Paula experimenta en sueños hipnóticos son la mayor clave para resolver el conflicto principal de la obra, las pesadillas y la solicitud de ayuda del espíritu. Además, son la preparación espiritual para un sueño aún más especial en el contexto de un ritual indígena de ayahuasca que lleva a la revelación final que resuelve todo el enigma. Con eso la novela promueve una actitud espiritual y filosófica, la fe en fenómenos como la telepatía, vidas pasadas y el acceso a conocimientos ocultos e incluso sanación en sueños. Así, es un manifiesto en contra del rumbo racionalista de las épocas modernas de las "post-luces" a partir del siglo XVIII del mundo occidental. Será que La Eternidad de la Rosa es una más de las novelas que proponen una (re-)espiritualización de las sociedades modernas como proyecto social. Será interesante seguir investigando esa posible corriente nueva que se puede nombrar "realismo espiritual" como lo que ahora viene después del realismo mágico.

\section{Referencias bibliográficas}

Amaringo, P. y Luna, L. E. (1999 [1991]). Ayahuasca Visions: The Religious Iconography of a Peruvian Shaman. Berkeley/California: North Atlantic Books. Algunos cuadros y también una descripción de los cuadros por el pintor en URL: https://headoverheels.org.uk/artwork/. Última consulta el 13-09-2018.

Anónimo (apodo Guancheman) (2010). Todo es amor. Mi experiencia con la Ayahuasca, puesto en línea 
el 16-12-2010, URL: http://www.onirogenia.com/enteogenos/todo-es-amor-mi-experienciacon-la-ayahuasca.pdf. Última consulta el 13-09-2018.

Barrett, Deirdre (1996). Trauma and dreams. Cambridge, Mass./London: Harvard University Press.

Cantilo, M. (2014). Jardines del Origen. Buenos Aires: Colihue.

Creighton, C. (2014). Ich sah Gott und ich war Gott, einfach alles war Gott - meine erste Erfahrung mit Ayahuasca, puesto en línea el 22-09-2014, URL: https:/www.vice.com/de/article/qbmvbq/ichsah-gott-und-ich-war-gotteinfach-alles-war-gott-meine-erste-erfahrung-mit-ayahuasca-554. Última consulta el 13-09-2018.

Engel, M. (2017). Towards a Poetics of Dream Narration (with examples by Homer, Aelius Aristides, Jean Paul, Heine and Trakl), en B. Dieterle y M. Engel (Ed.). Writing the dream/Écrire le rêve (pp. 19-44). Würzburg: Königshausen \& Neumann

Ette, O. (2012). TransArea. Eine literarische Globalisierungsgeschichte. Berlin/Boston: De Gruyter. Freud, S. (1899/1900). La interpretación de los sueños. (Orig. alemán: Die Traumdeutung). Numerosas ediciones.

Gómez Trueba, T. (1999). El sueño literario en España. Consolidación y desarrollo del género. Madrid: Cátedra.

H., M. (2016). 11 cosas que aprendí la primera vez que tomé ayahuasca, puesto en línea el 15-062016, URL: https://matadornetwork.com/es/11-cosas-que-aprendi-la-primera-vez-que-tomeayahuasca/. Última consulta el 13-09-2018.

Horatius Flaccus, Q. (siglo I a. C.). Carmina. Numerosas ediciones.

Kreuzer, S. (2014). Traum und Erzählen in Literatur, Film und Kunst. Paderborn: Fink, también puesto en linea el 13-08-2014, URL (en caso de acceso): https://content-select.com/media/ moz_viewer/54044654-63a4-4854-8023-2859b0dd2d03/language:de. Última consulta el 1309-2018.

Lazzarino, L. (2011). Mi experiencia con ayahuasca, puesto en línea el 10-09-2011, URL: http:// losviajesdenena.com/2011/09/experiencia-con-ayahuasca/. Última consulta el 13-09-2018.

Moschitta, G. y González Roma, L. (2016). La Eternidad de la Rosa. Buenos Aires: Hojas del Sur. Real Academia Española (2018). Diccionario de la lengua española. URL: http://dle.rae. 
es/?w=diccionario. Última consulta el 13-09-2018.

Solte-Gresser, C. (2011). Alptraum mit Aufschub. Ansätze zur Analyse literarischer Traumerzählungen, en S. Goumegou/M. Guthmüller (Ed.). Traumwissen und Traumpoetik. Onirische Schreibweisen von der literarischen Moderne bis zur Gegenwart (pp. 139-262). Würzburg: Königshausen \& Neumann. 139-262.

Zerpa, F. (2017). Señales en el cielo: Lo que nunca se contó. Ovnis, telepatía, mundos subterráneos y profecias. eBook: Sudamericana. 